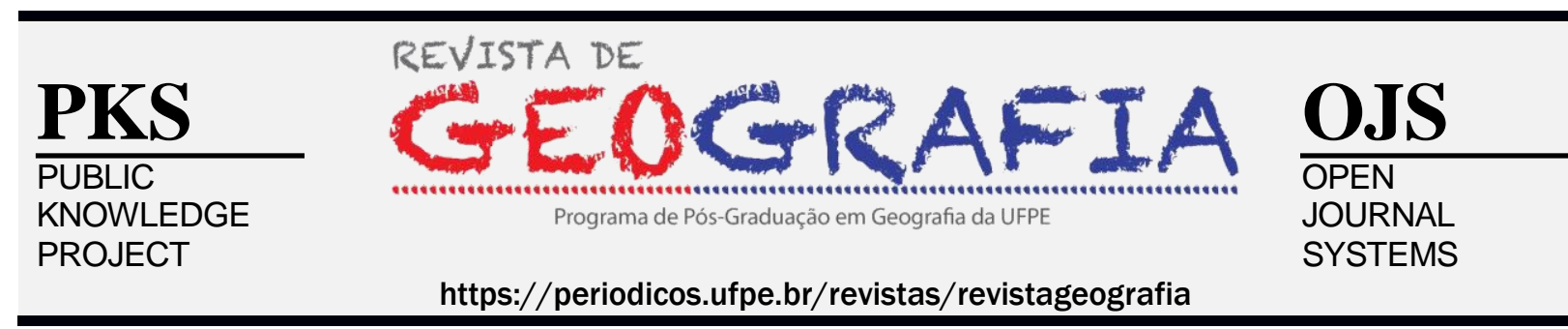

\title{
NAS TEIAS DO TERRITÓRIO: ANÁLISE DE ATORES, GRUPOS E REDES DE PODER EM IVAIPOR ̃̂A/PR
}

\author{
Cleiton Costa Denez ${ }^{l}$ Márcia da Silva ${ }^{2}$
}

\begin{abstract}
${ }^{1}$ Doutor em Geografia pela Universidade Estadual de Maringá (UEM). Membro do Grupo de Pesquisa Redes de Poder, Migrações e Dinâmicas Territoriais (GEPES).E-mail: cleiton.denez@hotmail.com

${ }^{2}$ Professora Doutora da Universidade Estadual do Centro-Oeste (UNICENTRO). É líder do Grupo de Pesquisa em Estudos Políticos e Análise Urbano-Regional e membro do Grupo de Pesquisa Redes de Poder, Migrações e Dinâmicas Territoriais (GEPES). E-mail: marcia.silvams@gmail.com
\end{abstract}

Artigo recebido em 31/07/2018 e aceito em 09/03/2019

DOI:

\section{RESUMO}

Nas teias do território tem o objetivo de representar e analisar as redes de poder que se estabelecem para o controle de determinado território com a identificação dos atores, grupos políticos e suas vinculações com o caso de Ivaiporã/PR. Para tanto, foi aplicado o método de representação por sociogramas de rede social que analisa os atores e suas vinculações em forma de rede de poder político, com auxílio de softwares. Este modelo de análise resultou na identificação dos principais atores e grupos políticos que atuam no município de Ivaiporã/PR (Grupo do PT, Grupo do PMDB e Grupo Papin), onde os mesmos produzem diferentes territorialidades, enquanto estratégia para controle do território de acordo e a depender dos diferentes vínculos estabelecidos.

Palavras-chave: Sociograma; Vínculos; Política; Município; Territorialidades.

\section{IN THE TEAS OF THE TERRITORY: ANALYSIS OF ACTORS, GROUPS AND NETWORKS OF POWER IN IVAIPOR $\tilde{A} / P R$}

\begin{abstract}
In the territorial webs, the objective is to represent and analyze the networks of power that are established for the control of a given territory with the identification of the actors, political groups and their links with the Ivaiporã/PR case. For that, the method of representation by sociograms of social network was applied that analyzes the actors and their connections in the form of a network of political power, with the aid of softwares. This model of analysis resulted in the identification of the main actors and political groups that work in the municipality of Ivaiporã/PR (PT Group, PMDB Group and Papin Group), where they produce different territorialities, as a strategy to control the territory of agreement and to depend different established links.
\end{abstract}

Keywords: Sociogram. Links. Politics. County. Territorialities. 


\section{INTRODUÇÃO}

O município de Ivaiporã, norte central paranaense, assim como demais municípios, esferas de poder e territórios, define-se como ambiente social, formado por diferentes segmentos e atores territorializados, que possuem as mais diversas aspirações em relação a forma que se deve produzir e ordenar o território que dividem, a depender dos interesses e visões de mundo. Assim, o estabelecimento de disputas entre os diferentes atores que se aglutinam e compõem grupos de acordo com interesses comuns produzem redes e práticas para controlar determinados segmentos. Como por exemplo, por meio das empresas, comércios, indústrias, sindicatos, escolas, associações e etc., produzindo as teias para domínio do território.

A produção e ordenamento de territórios ocorrem pelos encaminhamentos políticos que são adotados pelos grupos de poder, tornando esta problemática importante no que tange à forma como determinados atores se organizam, enquanto grupos políticos para o exercício do poder e o domínio do território. Dessa forma, apresenta-se a seguinte hipótese para interpretação das relações de poder sobre determinada área: a composição dos grupos de poder estabelece redes por meio das relações estabelecidas entre os atores políticos que determinam estratégias e objetivos em comum para dominar o território. Assim, a pesquisa foi norteada por uma revisão bibliográfica sobre o conceito de território, para explicar as relações de poder que se estabelecem no interior do território (HAESBAERT, 2006; MILLS, 1998; RAFFESTIN, 1993, 2009; SAQUET, 2004, 2009, 2010, 2011; SOUZA, 1995; SOUZA, 1997, WEBER, 1983, 1986 e 2016).

O objetivo desta pesquisa se pauta em identificar os atores e grupos políticos de Ivaiporã/PR, suas vinculações e a Análise de Redes Sociais (ARS) que se estabelecem para o controle do território. Identificar os atores políticos de Ivaiporã foi o primeiro passo para delimitar os grupos de poder e suas tessituras para a disputa e dominação do território. Os atores e grupos políticos se organizam para travar o processo de disputa sobre o espaço, neste estudo de caso o município de Ivaiporã é exemplo de palco do enfrentamento entre os grupos políticos que disputam entre si para exercer poder sobre o território.

Foram desenvolvidas entrevistas para levantamento de informações com o objetivo de identificar as vinculações entre os atores políticos e o processamento dos dados por meio dos softwares Ucinet e Gelphi, para a produção do sociograma da rede de poder político de Ivaiporã (ALEJANDRO\&NORMAN, 2005; DENEZ, 2016; FURINI, 2008; HANNEMAN, 2005; NAZARENO, 2005; MALAGOLLI, 2010). 
É essencial compreender na rede, a partir da abordagem utilizada, que o poder é relacional, e que só se exerce poder na relação de influência e/ou dominação do outro. A rede de atores para determinada finalidade constituí territorialidades, já que são estabelecidas relações entre os atores para influenciar locais e pessoas e, assim, se apropriar, dominar ou resistir no território a partir da tessitura que se estabelecem e o projeto que predomina sobre as demais territorialidades e forças políticas. Assim, cada grupo se organiza com determinados atores, que possuem o controle de determinados recursos, práticas e ideologias para impor o projeto que atende seus interesses sobre o território.

Discutem-se os recursos e práticas dos atores e grupos na teia política, já que cada ator está inserido em um segmento ou local da/na sociedade, se vinculando a mais atores, que possuem acesso a outras áreas e a outros atores, que produzem constrangimentos sobre determinadas áreas em contraposição a outros atores e redes que não se identificam com os mesmos que resistem e vetam as ações a depender das tessituras estabelecidas.

Por fim, a partir das entrevistas foram identificados oitenta e um (81) atores políticos presentes em Ivaiporã e três principais grupos políticos (grupo do PT, Grupo do PMDB e grupo Papin) e sub-agrupamentos articulados na rede representada no sociograma produzidos pelos softwares que possibilitaram analisar um pouco das relações de poder que se estabelecem na disputa, dominação e apropriação do território com o caso de Ivaiporã.

\section{REDES DE PODER, TERRITÓRIO E TERRITORIALIDADES}

Para Raffestin (1993, p. 157) "Toda rede é uma imagem do poder ou, mais exatamente, do poder do ou dos atores dominantes". É o que se pretende a partir do presente trabalho, revelar a teia de poder que se projetam sobre o território do município de Ivaiporã, os atores, os grupos e as principais estratégias políticas dos atores e suas territorialidades na dominação do território.

Como estudo clássico revelador desta ótica de análise, para além da vasta literatura acumulada sobre o tema e que trouxe contribuições para a análise de processos semelhantes, não poderia deixar de mencionar o clássico livro de Wright Mills, “A elite do poder” (1968). $\mathrm{O}$ autor aborda a elite do poder nos Estados Unidos, afirmando que a mesma é formada por três grandes ordens, ou um triângulo composto pelos políticos, militares e empresários que, interligadas, influenciavam as instituições menos expressivas de uma complexa rede social (igrejas, escolas etc.), objetivando legitimar suas ações de perpetuação no poder. O debate 
proposto na obra apreende o como as decisões políticas determinam as atividades econômicas e os programas militares naquele país, bem como o acesso aos mesmos, rigorosamente controlado pela elite do poder, para a qual, basicamente, permite-se apenas a entrada de seus pares.

Assim, é necessário considerar os atores envolvidos com os grupos de poder e a produção de territorialidades conforme destaca Saquet (2004), lembrando que a mesma relaciona-se com a identidade e com as relações de afetividade por meio também de um campo simbólico. As territorialidades têm como resultado a territorialização e, no território, há diferentes campos de força, diferenciando-o dos demais e dando-lhes homogeneidade e heterogeneidade a partir da construção da identidade territorial, sendo assim necessário ter como variante o campo simbólico na constituição das teias do poder.

Raffestin (2009), afirma que os territórios e territorialidades são produzidos a partir da combinação de vários elementos e atores, que estão à disposição do sistema. Em cada situação há elementos e atores específicos. A construção de territorialidades se dá por meio das relações que se produzem ao se constituir um território e que se reproduzem em seu interior ao longo do tempo. A territorialidade dessa maneira "tem alterações no tempo histórico, no mesmo e em diferentes lugares, de maneira relacional" (SAQUET, 2010, p. 149). Para se compreender o exercício de poder sobre o território, levam-se em conta as territorialidades que os grupos de poder produzem sobre determinado território, no caso, o município de Ivaiporã.

Para a análise da teia de poder de Ivaiporã, concorda-se com Silva (2005, p. 196): "Cabe dizer que a rede aqui trabalhada, a rede social, se forma e é construída em razão de um objetivo comum, o da conquista do poder político, econômico e/ou simbólico". A autora destaca o conceito de rede social e o emprega para análise dos territórios conservadores de poder em Guarapuava. Nesse local utilizou as redes sociais como metodologia para análise dos grupos políticos, além disso, foram elaborados esquemas interpretativos e sociogramas inserindo os atores ao conjunto da rede.

Cada ator se insere na teia com a sua importância, porém, é necessário levar em conta a produção das relações que estabelecem com outros atores e o posicionamento de cada um na rede. A posição, articulações e vínculos de cada ator determinam o controle e a influência sobre determinadas pessoas e o território. Para Raffestin (1993, p. 151), os atores territorializados produzem relações e estabelecem redes para assegurar o controle do território, sendo a base para o desenvolvimento das relações de poder: "Esses sistemas de 
tessituras, de nós e de redes organizadas hierarquicamente permitem assegurar o controle sobre aquilo que pode ser distribuído, alocado e/ou possuído" (RAFFESTIN, 1993, 151).

Nazareno (2005), ao estudar as redes sociais e coalizões de governo em Curitiba, destaca que é necessário compreender o conjunto em que se inserem os atores na rede. Para a autora, a articulação dos atores em rede influencia a visão de mundo dos indivíduos. Portanto, há meios para influenciar as preferências que a rede alcança com seus atores e onde cada um se insere no seu dia-a-dia, atualizando a visão de mundo dos atores no campo simbólico na interpretação do real e assim possibilitando o controle e a dominação dos homens sobre os homens. Neste contexto, Raffestin (1993, p.58), lembra que "o poder visa o controle e a dominação sobre os homens e sobre as coisas". Para dominação dos homens e coisas se estabelecem relações sobre e para o controle, essas ações também se estabelecem sobre/no território. Sobre dominação territorial é possível se sustentar na obras de Weber (1983, 1986 e 2016), que tratam dos princípios da legitimidade do exercício de poder e a lógica racionalista e burocrática da sociedade moderna no processo de dominação e controle, que consiste em uma relação que se estabelece entre dominador e dominados, onde os que se submetem concedem a dominação por alguma razão considerada legitima que fundamente o poder de um sobre o outro. Miguel (2018), lembra que a "dominação" está no centro daquela que é, talvez, a contribuição mais influente de Max Weber para a teoria política. O autor ainda lembra que a "legitimidade" de Weber tenha por algum motivo ganhado mais destaque, porém é necessário diante das relações de poder dar atenção ao conceito oculto da legitimidade, ou seja, a dominação. É necessário, assim, voltar ao conceito de dominação de Weber para compreender o exercício do poder, como no presente estudo de caso, onde se utiliza o conceito aplicado ao território como forma de compreender a dinâmica das relações de poder apartir das tecituras desenvolvidas pelos grupos políticos.

Raffestin (1993), explica sobre o sistema territorial constituído por diferentes elementos como: nós, malhas e redes, sendo que toda ação e comportamento se traduzem por uma produção territorial, onde nenhuma sociedade escapa de organizar o campo operatório de sua ação. A organização em um sistema de malhas, nós, redes e tessituras permitem o controle sobre aquilo que pode ser distribuído, alocado ou possuído. Nessa estrutura, está a origem das relações de poder para Raffestin (1993).

É possível decifrar as relações de poder a partir dos atores sintagmáticos que estão para todos os níveis de organização, do Estado nacional até às micro organizações, como uma empresa ou até mesmo uma casa ou um quarto. O Estado ordena o seu território com novas 
ligações, pontos de informações e, assim, é, também, para quem ordena uma casa e seus móveis.

Neste trabalho, a disputa do território é analisada a partir das relações que estabelecem no seu interior, o qual é disputado por grupos de poder que possuem aspirações diferentes para o território, a depender dos segmentos e atores que compõem cada grupo. Cabe ampliar a escala de análise, citando o livro "Elite do atraso" de Jessé Souza (2017), para o qual, somente novas concepções sobre o Brasil e seu povo poderiam explicar que as raízes das desigualdades sociais, econômicas, políticas e territoriais não estão na formação de grupos que deram ao Estado uma herança de corrupção, mas na escravidão. Foram as relações de exploração ditadas por determinados grupos, de acordo com o autor, que permitiram a legitimação de interesses econômicos de uma elite que sempre mandou no mercado, este sim a real fonte de corrupção e poder, consubstanciando territórios desiguais. Neles, pode haver divisões e interesses diferentes e divergentes, em que um grupo domina o território em detrimento do outro, cabendo, assim às territorialidades para interpretar as relações internas do território.

Na representação da rede social, cada pessoa é concebida como um nó. Todo ator se vê e se representa como um centro. O ponto é de certa forma, a expressão de todo ego, individual ou coletivo (RAFFESTIN, 1993, p. 156). Os nós para Raffestin (1993) são locais de poder e de referência. Os vínculos são representados pelas conexões entre linhas e colunas da matriz produzidas com as informações e base de dados na representação da rede social. Os atores estarão ligados a partir da relação que se estabelecem entre dois e mais. "O que importa saber é onde se situa o Outro, aquele que pode nos prejudicar ou nos ajudar, aquele que possuí ou não tal coisa, aquele que tem acesso ou não a tal recurso etc.” (RAFFESTIN, 1993, p. 156). A representação permite saber onde se situam os atores, as vinculações e os recursos dispostos.

Interpretar o sistema territorial por meio das redes sociais possibilita identificar os atores, compreender a posição dos mesmos e as tessituras produzidas. Para Raffestin (1993) a produção e organização do território passam por atores sintagmáticos, do Estado (tessitura) ao indivíduo (nó). Para noção de tessitura implica a noção de limite, o alcance das tessituras estabelece os limites de alcance.

O estabelecimento das tessituras entre os atores gera a delimitação de ação de um grupo, produzindo malhas. O município de Ivaiporã pode ser interpretado a partir de uma malha, pois, a rede de poder de Ivaiporã pode ser integrada, já que há atores intermediários 
que vinculam todos os grupos formando uma complexa teia de poder. Os atores alcançam os limites do município, a área de atuação dos atores políticos locais, mesmo com a presença de atores de atuação estadual e nacional, ocorre sobre o território de Ivaiporã que é o recorte de análise a malha de tessitura das relações de poder.

Nesse sentido, temos Ivaiporã como a principal malha, o campo de atuação dos atores políticos, onde se estabelecem as relações e tessituras para a disputa do território. Então, há vários atores e grupos que disputam o mesmo território. "Mas, esses atores não se opõem; agem e, em consequência, procuram manter relações, assegurar funções, se influenciar, se controlar, se interditar, se permitir, se distanciar ou se aproximar e, assim criar redes entre eles" (RAFFESTIN, 1993, p. 156).

A vida é uma teia de relações entre determinados atores constituindo territorialidade que delimitam, identificam e compartimentam o território, sendo de certa forma para Raffestin (1993): “a face vivida" da "face agida” do poder. É necessário compreender a rede de poder de Ivaiporã como um todo e, ao mesmo tempo, as particularidades internas, compartimentações, tessituras, demarcações que se estabelecem entre os diferes nós e grupos.

Para Furini (2008), a análise das redes sociais identifica aspectos relativos ao espaço, como no nosso caso que se utiliza Ivaiporã como recorte para interpretar as relações sociais que se estabelecem nesse local. As relações e ações no estabelecimento de vínculos entre os atores ocorrem sobre o espaço, produz territórios e territorialidades, já que é na mesma rede e território que se trava a disputa para controlar mais pessoas, recursos e, assim, decidir a maioria das ações sobre o território em detrimento aos atores/grupos que possuí menor influência e tessitura na rede.

Souza (1995), destaca que o território é um "campo de força”, uma: "dimensão do espaço social", neste ponto ele é "intangível” e "intocável” (SOUZA, 1995, p. 66), ele é imaterial, no entanto, é a expressão do poder sobre o espaço. O território é o espaço apropriado por grupos humanos que se utilizam dos seus recursos e estabelecem características culturais a esse espaço, inseridas as relações de poder e nos conflitos que o envolvem. "[...] o território é o produto de uma relação desigual de forças, envolvendo o domínio ou o controle político-econômico do espaço e suas apropriações simbólicas, ora conjugadas e mutuamente forçadas, ora desconectadas e contraditoriamente articuladas" (HAESBAERT, 2006, p. 121).

$\mathrm{Na}$ apropriação do espaço, o exercício do poder é um campo de ação que se modifica no espaço-tempo por meio da conjugação e contraposição de forças sobre o espaço. Ao 
analisar a história, observa-se que a apropriação do espaço para a sobrevivência sempre esteve em posse de determinados grupos, levando à exclusão de outros e, assim, sua existência se dá pela contradição.

Para tanto é necessário traçar alguns encaminhamentos metodológicos para apreender, representar e analisar as complexas teias de poder que se projetam para produção de territórios.

ENCAMINHAMENTOS METODOLOGICOS: aprensão, representação e interpretação das teias de poder

A interpretação das redes sociais é elaborada a partir de sociogramas que produzidos com auxílio dos softwares Ucinet e Gelphi. Para a aprensão de informações e dados é necessário levantar informações iniciais associadas com entrevistas, para identificar os atores e a vinculação dos mesmos. Os softwares são utilizados para cálculo das matrizes que produzem os sociogramas com a relação de atores para determinados fins.

Os procedimentos metodológicos seguiram o proposto por Hanneman (2001) que, representam graficamente as relações sociais de forma matemática, porém os cientistas sociais denominaram esses gráficos de sociogramas. "Por fim, esses sociogramas possibilitam acesso a conhecimentos nem sempre apreendidos, enquanto relações difíceis de captar sem uma representação detalhada e contextualizada" (FURINI, 2008, p. 188).

Para identificar as redes estabelecidas para a disputa do território em Ivaiporã, utilizou-se o resultado das eleições de 2000 a 2012, em que foram selecionados os principais atores políticos do município, de acordo com os participantes das eleições majoritárias de acordo com o número de votos com dados do Tribunal Regional Eleitoral.

Os dados dos resultados das eleições, como os principais atores, foram utilizados como base para organizar roteiros a partir de uma lista matriz para entrevistas, visando identificar a vinculação entre diferentes atores. É importante frisar que pode ocorrer que determinados atores não sejam mencionados e, assim, não identificados na rede, assim como, a superestimação de conectividade com a citação de vínculos.

Foi solicitado que os entrevistados indicassem mais atores políticos vinculados aos da lista, de forma que fossem incorporados à lista para as próximas entrevistas. O método utilizado é chamado de snowball (HANNEMAN, 2001), ou seja, uma bola de neve, em que a cada entrevista se acrescenta mais informações, aumentando a rede, que não tem uma predefinição de tamanho e aumenta de acordo com novas indicações de atores. 
Assim, as entrevistas continuam, até que se esgotaram as possibilidades de novos atores ou se decida parar. As entrevistas foram aplicadas a trinta pessoas de diferentes segmentos de Ivaiporã ligados ao meio político: funcionários efetivos e comissionados da prefeitura de Ivaiporã, assessores de vários vereadores e de diferentes partidos e grupos políticos; profissionais liberais de diferentes áreas, médicos, advogados, professores e comerciantes, que participam e conhecem os atores políticos do município.

As entrevistas foram realizadas entre março a junho de 2015, o número amostral de trinta (30) foi utilizado não como um limite, pois, as mesmas poderiam continuar, porém, os nomes se repetiam de acordo com as novas entrevistas e cada vez mais surgia atores do cenário político estadual e até nacional. Assim, se optou por encerrar as entrevistas identificando os oitenta e um (81) atores ${ }^{1}$ para a rede, que são representados como os nós e interligados por linhas de acordo com as indicações dos entrevistados. Para Malagolli (2010), os atores constituem a estrutura da rede em que estão presentes as relações de poder, influência, interesses, confiança e as negociações.

Para Raffestin (1993, p.157): "são as redes que asseguram o controle do espaço e o controle no espaço. Entre uma série de pontos há uma infinidade de possibilidades, mas somente com três pontos, se tem oito possibilidades". Quanto mais nós, maiores são as possibilidades, as estratégias são numerosas. Porém, pelos recursos disponíveis é um conjunto finito.

"Um indivíduo não tem poder em abstrato, ele têm poder, porque ele pode dominar os outros - o poder do ego é a dependência de alteridade" (HANNEMAN, 2001, p. 8). Para Hanneman (2001), o mais importante na rede é compreender, a partir da abordagem utilizada, que o poder é relacional, e que só se exerce poder na relação de influência e/ou dominação do outro. A representação da rede social permite, pelo grau de centralidade, intermediação e proximidade, interpretar as relações de dominação, já que revelam os atores centrais que se conectam com mais atores. A intermediação demonstra os atores que possibilitam a conexão entre diferentes atores e a proximidade que identifica os atores que estão com as melhores

\footnotetext{
${ }^{1}$ Para analisar os sociogramas é necessário qualificar com mais informações sobre os atores identificados. Além dos dados quantitativos, as entrevistas rementem a necessidade de informações qualitativas sobre os atores que foram surgindo de acordo com as aplicações das entrevistas e acrescentadas ao logo deste texto nas notas de roda-pé de acordo com as citações do atores políticos da rede. Entre os atores identificados há referências externas a Ivaiporã, que se vinculam aos atores locais, como deputados, senadores, ministros e etc.
} 
posições na teia. Existem, portanto, atores que possuem posições privilegiadas na rede social que se vinculam e controlam os demais.

O posicionamento do ator potencializa ou veta a ampliação de tessituras dos grupos que se estabelecem na rede social, o favorecimento do posicionamento de determinado ator o coloca em situação privilegiada para se vincular com os demais atores e assim exercer poder. Os diferentes atores que se apresentam e formam um grupo, podem possuir acesso a determinados espaços e segmentos da sociedade, contribuindo para controlar determinada área e, assim, evitar o controle por parte de outros atores/grupos por meio das territorialidades que produz e, ao mesmo tempo, reproduzi-las por ocupar determinados espaços.

Os atores que compõem determinado grupo produzem uma identidade homogeneizadora por intermédio dos discursos e práticas, o que possibilita, de certa forma, controlar/influenciar pessoas que estão em volta ou que possuem acesso. Tal controle funciona porque as pessoas se identificam com os discursos e práticas do grupo "A", por exemplo, isso porque o grupo consegue chegar a determinadas pessoas, como nas escolas, fábricas, praças, pelas ondas do rádio e etc. e o grupo "B" ou " $C$ " não possuí o mesmo sucesso, já que pode não possuir pessoas, vínculos e, consequentemente, as territorialidades necessárias para estar e controlar os espaços nos cenários apresentados.

Determinado discurso vai chegar à escola se tiver um meio para tanto, assim, se torna mais fácil se houver várias pessoas nesse espaço que reproduzam o discurso do grupo “A”, o que pode não acontecer com o grupo "B" porque o mesmo não tem entrada nesse espaço, ou entrada limitada, ou até mesmo entrada por outros canais, como os meios de comunicação. Nesse sentido, podemos destacar que o grupo "B" possuidor do controle das emissoras de rádios e jornais, possui outros meios que o seu discurso chegue a determinado público e o controle de determinados espaços de forma diferente do grupo "A".

A situação exposta acima ocorre em Ivaiporã, assim como em outros municípios, espaços e escalas geográficas, nos quais se disputam o exercício do poder. O fato de controlar áreas, disputá-las, demarcar campo com a produção de identidades e diferentes práticas e relações sociais é uma forte expressão do que é territorialidade.

Identificar os atores, as relações, vínculos e tessituras estabelecidas entre os atores é possível com a representação dos sociograma da rede social, no nosso caso utilizando o Ucinet e o Gelphi, bem como estabelecer quais as territorialidades se desenham no interior da teia de poder, a partir do alcance de determinadas tessituras e da produção de identidades para assegurar o exercício do poder sobre determinado território. 


\section{A REPRESENTAÇÃO DE TEIAS DO PODER: $o$ caso de Ivaiporã/PR}

$\mathrm{Na}$ rede de poder de Ivaiporã, apresentada no sociograma, podem ser identificados três principais grupos políticos ${ }^{2}$ (Fig.1). Em vermelho está representado o grupo do Partido dos Trabalhadores (PT), em verde o grupo do Partido do Movimento Democrático Brasileiro (PMDB) e em amarelo o grupo Papin e em laranja está evidenciada a posição de Sérgio Chaves $^{3}$ que não se configura como grupo, mas como ator com vinculações de intermediação entre os diferentes grupos e assim os atores que se apresentam na mesma cor.

O grupo do Partido dos Trabalhadores representado no sociograma é uma composição de atores de diferentes partidos e segmentos, só recebe a denominação de Partido dos Trabalhadores, por ser o partido e o grupo que lidera a aglutinação de outros grupos menores. Podem ser citados pertencentes a esse grupo o Partido Democrático Trabalhista (PDT) e o Partido Social Cristão (PSC) como os principais partidos, já as frações de segmentos que o compõem são professores e funcionários da rede estadual de ensino e de outros segmentos vinculados à educação, pequenos comerciantes, agricultores familiares e lideranças religiosas.

Nas eleições de 2000 houve aliança entre o PMDB e o PT, no grupo de Geomar Torres $^{4}$, nó de intermediação que vincula o Partido dos Trabalhadores com o PMDB, fazendo com que o PT não fique isolado dos demais produzindo uma rede desvinculada do restante. $\mathrm{O}$ maior grau de intermediação entre PT e o grupo do PMDB é Sérgio Chaves, seguido por Geomar Torres e Celestino $\mathrm{Jr}^{5}$. Assim, Sérgio Chaves é um nó que contribuí para manter a vinculações entre o PMDB e o PT, se tornando um ator de poder por ter entrada em alas dos

\footnotetext{
${ }^{2}$ A qualificação de grupo para o Partido dos Trabalhadores e para o Partido do Movimento Democrático Brasileiro foi a opção para identificar os grupos políticos do município, quando se trata do grupo do PT e do grupo do PMDB não se referimos apenas a sigla partidária institucionalizada, mas ao agrupamento que reúne diferentes partidos, segmentos e etc. que ficou, a princípio, melhor caracterizado com a sigla, o mesmo não ocorre com o grupo Papin, que ficou melhor caracterizado e identificado como nome da família, do que pelo partido principal do grupo que era no momento o PSDB.

${ }^{3}$ Eliaquim Sérgio Chaves, professor da rede estadual de ensino do Paraná; vereador em 1982 pelo PMDB e 1988 pelo PTB. Chefe do Núcleo Regional de Educação de Ivaiporã no governo Roberto Requião (PMDB); expresidente do núcleo da APP/Sindicato Ivaiporã; ex-presidente da APAE. Candidato a vice-prefeito pelo PT na chapa de Celestino Jr (PPS) em 2016.

${ }^{4}$ Geomar Torres Pereira, engenheiro civil; vice-prefeito na chapa do Pe. Luizinho (1996/2000); candidato a prefeito em 2000 e 2004 pelo Partido Popular Socialista (PPS).

${ }^{5}$ Celestino Alves de Souza Junior, membro da Assembleia de Deus, filho de Celestino Alves de Souza; eleito vereador em 2000 pelo PMDB, candidato a deputado estadual em 2002 pelo PMDB; irmão de Carlos Celestino (candidato a vereador em 2012 pelo PPS). 
dois grupos políticos. Assim, podemos evidenciar que os principais nós do PT são: Cyro Fernandes ${ }^{6}$ e Nadir Maciel $^{7}$, respectivamente.

Em verde se apresenta os nós polarizados pelo PMDB, é possível verificar a polarização de uma maior quantidade de nós e com alto grau de centralidade, como o caso de Carlos Gil $^{8}$, Pessuti ${ }^{9}$, Zé Balão ${ }^{10}$ e Célio Pereira ${ }^{11}$, que demonstram uma maior concentração de entrada de vínculos ${ }^{12}$ no centro da rede. Apresenta-se como o maior agrupamento da rede, onde as tessituras alcançam grande parte da rede política.

O ideal de empreendedorismo, juntamente com capacidade administrativa demarca campo político e identifica o grupo de Carlos Gil e agrega demais atores. A construção simbólica em torno do ator e grupo político, mais a articulação em redes controlando diferentes atores e espaços, formam territorialidades. O partido, os atores e a significação de cada um, na sociedade ivaiporaense, ao se agruparem produzem territorialidade, determinadas famílias possuem identidades vinculadas a cidade, no caso da família Gil o ideal de empreendedorismo, de progresso e desenvolvimento são assimilados e reproduzidos no grupo político de Carlos Gil. Nesse aspecto, “o estudo analítico dos ricos e poderosos é, antes de qualquer coisa, o estudo sobre uma ampla rede social e política de interesses. Muitas vezes as conexões e os capitais sociais e políticos são acumulados ao longo de diversas gerações" (OLIVEIRA, 2012, p. 125). A família Gil, em Ivaiporã, está inserida em uma rede de interesses, a princípio pode-se evidenciar os vínculos com Orlando Pessuti e com demais atores do PMDB de Ivaiporã, porém, as relações econômicas se tornam complexas a medida que a família possui capital e diversos empreendimentos.

\footnotetext{
${ }^{6}$ Cyro Fernandes Correa: professor de ciências sociais, candidato a vereador, a vice-prefeito chapa de Geomar Torres em 2004 e a deputado estadual e federal pelo PT. Eleito vereador em 2000 e prefeito de Ivaiporã em 2008 pelo PT.

${ }^{7}$ Empresária e comerciante, membro da Câmara da mulher empreendedora (SESC/SENAC); secretária de indústria e comércio na gestão de Cyro Fernandes (2009/2012). Vereadora eleita em 2012 e candidata a deputada estadual pelo PT em 2014.

${ }^{8}$ Luiz Carlos Gil, empresário, proprietário do grupo Comercial Ivaiporã. Candidato a vereador em 1988 e eleito prefeito em 2012 pelo PMDB.

${ }^{9}$ Orlando Pessuti, médico veterinário, eleito deputado estadual pelo PMDB em 1982, 1986, 1990, 1994 e 1998. Eleito vice-governador em 2002 e 2006. Governador do estado do Paraná em 2010, ocupando a vaga do titular Roberto Requião (PMDB).

${ }^{10}$ José Narciso de Melo, vereador pelo PL em 1988 e reeleito pelo PST em 1992; candidato a vice-prefeito em 1996 na chapa de Pedro Papin, em 2000 foi candidato a vice na chapa de Geomar Torees (PPS) e eleito viceprefeito em 2004 na chapa de Célio Pereira e candidato a prefeito em 2008 pelo PMDB.

${ }^{11}$ Conhecido por Célio Boaideiro, pecuarista, eleito vice-prefeito pelo PTB, no ano 2000, na chapa de Pedro Papin, Prefeito, em 2003, a partir da cassação do titular Pedro Papin e eleito prefeito pelo PMDB em 2004.

12 Os atores que recebem o maior o número de vínculos são os que receberam o maior número de citações de outros atores que se vinculam ao mesmo nas entrevistas, tornando estes nós os maiores na representação da rede de poder no sociograma da figura 01. 
A família Gil é proprietária do grupo Comercial Ivaiporã, loja de materiais de construção que possui rede em vinte e três (23) cidades do Paraná. Além da empresa Comercial Ivaiporã, a família é proprietária de outros empreendimentos, como o hotel Vilhar, a Castelo Matérias de Construção, Pedreira Ivaiporã, Cine Ivaiporã e etc. O aparato econômico da família Gil é recurso estratégico para assegurar apoio político.

Para Oliveira (2012, p. 125): “A ação social e econômica dos dominantes fundamenta-se em torno dos aparelhos de Estado, como forma direta e indireta de controles do fluxo de informações, capitais e privilégios essenciais para a reprodução ampliada da classe dominante". Esse mesmo autor aponta que os ricos e poderosos possuem posições privilegiadas pela participação nos diferentes espaços de poder do Estado. Por outro lado, destaca que toda pobreza também é fruto de falta de políticas do estado de combate à pobreza. “Toda forma de grande riqueza, grande patrimônio e grande poder político é fundamental em relações privilegiadas em diferentes espaços de poder centrados no estado" (OLIVEIRA, 2012, p. 125).

A partir de Oliveira (2012) é possível compreender porque Carlos Gil é um ator em potencial, primeiro porque o aparato econômico da família garante estratégias que facilitam a disputa de poder com outros grupos, segundo porque é produzida uma rede política como ocorre com Orlando Pessuti, produzindo conexões de interesses envolvendo empresário e cargos políticos no aparelho do estado.

A família Gil, somada ao grupo empresarial da família, Comercial Ivaiporã, mais o grupo do PMDB, Orlando Pessuti/Zé Balão/Sérgio Souza ${ }^{13}$ e, ainda, a vinculação com o médico Adail Rother Junior ${ }^{14}$, filho do ex-prefeito Adail Rother, forma o grupo político institucionalizado pelo PMDB em Ivaiporã. O grupo empresarial e a história da família contribuem para a idealização e construção ideológica, assim como dos atores políticos que se somam ao PMDB e a outros partidos da coligação PMDB/PP/PTB/PHS/PSB/PSD/PT do B ${ }^{15}$. É necessário ressaltar que os partidos representam a forma institucional de organização de blocos de poder para a disputa eleitoral, toda via, para além dos partidos, os grupos são constituídos por estratos de classes, segmentos, grupos familiares, econômicos, sociais e etc.

\footnotetext{
${ }^{13}$ Assessor parlamentar de Orlando Pessuti, suplente de Senador de Gleisi Hoffmann (PT) eleito em 2010, eleito deputado federal pelo PMDB em 2014.

${ }^{14}$ Adail Rother Junior, médico; filho de ex-prefeito Adail Rother. Eleito vice-prefeito na chapa de Carlos Gil pelo PMDB em 2012. Filiou-se ao PSDB em 2013.

${ }^{15}$ Coligação Para Frente e para todos apresentada pela chapa para prefeito de Ivaiporã por Carlos Gil e Adail Rother

Denez e Silva, 2019.

ISSN 0104-5490

184
} 
Dessa maneira, Carlos Gil representa o alto empresariado de Ivaiporã, aliado à Dr. Adail, que representa frações de profissionais liberais da alta classe média e, ainda, o apoio político de figuras tradicionais, como o próprio Pessuti, Alex Canziani ${ }^{16}$ (PTB), Ademar Traiano $^{17}$ (PSDB) e etc., essas várias nuances e vareiantes identificam o conteúdo do PMDB de Ivaiporã

O grupo pemedebista ivaipoiraense é diverso e com diferentes alas e com mais partidos aliados que formam o grupo. Existe o grupo de Carlos Gil, cercado pelo grande empresariado de Ivaiporã, que se aproxima do Partido da Social Democracia Brasileira (PSDB). A ala de Orlando Pessuti composto pelos pemedebistas tradicionais, dividido pela presença de Flávio Teixeira ${ }^{18}$. Há ainda, outros grupos como os vinculados aos deputados Alexandre Curi $^{19}$ e Artagão Junior ${ }^{20}$, como Eder Moraes que é do Partido Humanista da Solidariedade (PHS) e Sabão que é do Partido Trabalhista Brasileiro (PTB), também vinculado ao deputado federal Alex Canziani do PTB, Ilsinho ${ }^{21}$ do Partido Progressista (PP) e o vereadr Bonitinho ${ }^{22}$, anteriormente eleito pelo PT e depois filiado ao Partido Republicano da Ordem Social (PROS), compondo a base do Prefeito Gil na Câmara de Vereadores.

Em amarelo está representada na rede a polarização realizada pelo grupo de Pedro Papin $^{23}$, é o menor agrupamento, porém se encontra entrelaçado com o grupo do PMDB, justamente por a maior parte dos nós polarizados pelo PMDB possuírem no passado vinculação com o grupo de Papin. Pedro Papin se elegeu vereador em 1992 pelo PMDB, depois passou a disputar a prefeitura pelo PTB/PSDB. Os principais nós do grupo são: Pedro Papin e Jaffer ${ }^{24}$, as principais vinculações são de parentesco da família Papin, caracterizando

\footnotetext{
${ }^{16}$ Advogado, vereador em Londrina eleito em 1988 e 1992; eleito vice-prefeito em 1996 na chapa de Antônio Belinati; secretário de estado do governo Jaime Lerner; eleito deputado federal em 2002, 2006, 2010 e 2014 pelo PTB.

${ }^{17}$ Ademar Traiano, ex-prefeito de Santo Antônio do Sudoeste em 1986; eleito deputado estadual em 1990 para cinco mandatos consecutivos. Atualmente é filiado ao PSDB, presidente da Assembleia Legislativa (2015/2018).

${ }^{18}$ Flávio Pereira Teixeira, advogado; candidato a vice-prefeito pelo MDB em 1972, candidato a prefeito pelo MDB em 1976; eleito prefeito pelo PMDB em 1982; candidato a prefeito em 1992 e 1996 pelo PMDB.

${ }^{19}$ Neto de Aníbal Curi, vereador em Curitiba em 2000, deputado estadual em 2002, 2006, 2010 e 2014.

${ }^{20}$ Artagão de Mattos Leão Junior, formado em direito; Filho do ex-deputado estadual Artagão de Mattos Leão e atual conselheiro do Tribunal de Contas; eleito deputado estadual em 2002, 2006, 2010 e 2014 pelo PMDB.

${ }^{21}$ Ilson Doinizete Gangliano, servidor municipal da secretaria de Saúde; Secretário Municipal de Saúde na gestão Célio Pereira (2005/2008). Vereador eleito em 2012 pelo PP.

${ }^{22}$ Sebastião Bonfim Matos, servidor público municipal; eleito vereador em 2008 e 2012 pelo PT, atualmente no PROS.

${ }^{23}$ Pedro Wilson Papin, empresário; Vereador (1992/1996 pelo PMDB); Candidato a prefeito em 1996 pelo PTB; prefeito eleito (2001/2004) pelo PTB; Candidato a prefeito em 2004 e 2008 pelo PSDB.

${ }^{24}$ Jaffer Guilherme Saganski Ferreira, vereador em 2008 e candidato a prefeito em 2012 pelo PSDB. Genro de Pedro Papin. 
o grupo por relações de nepotismo ${ }^{25}$. O secretariado de Papin e as nomeações nos cargos das regionais do governo do estado em Ivaiporã, indicados pelo mesmo, revelam tal prática.

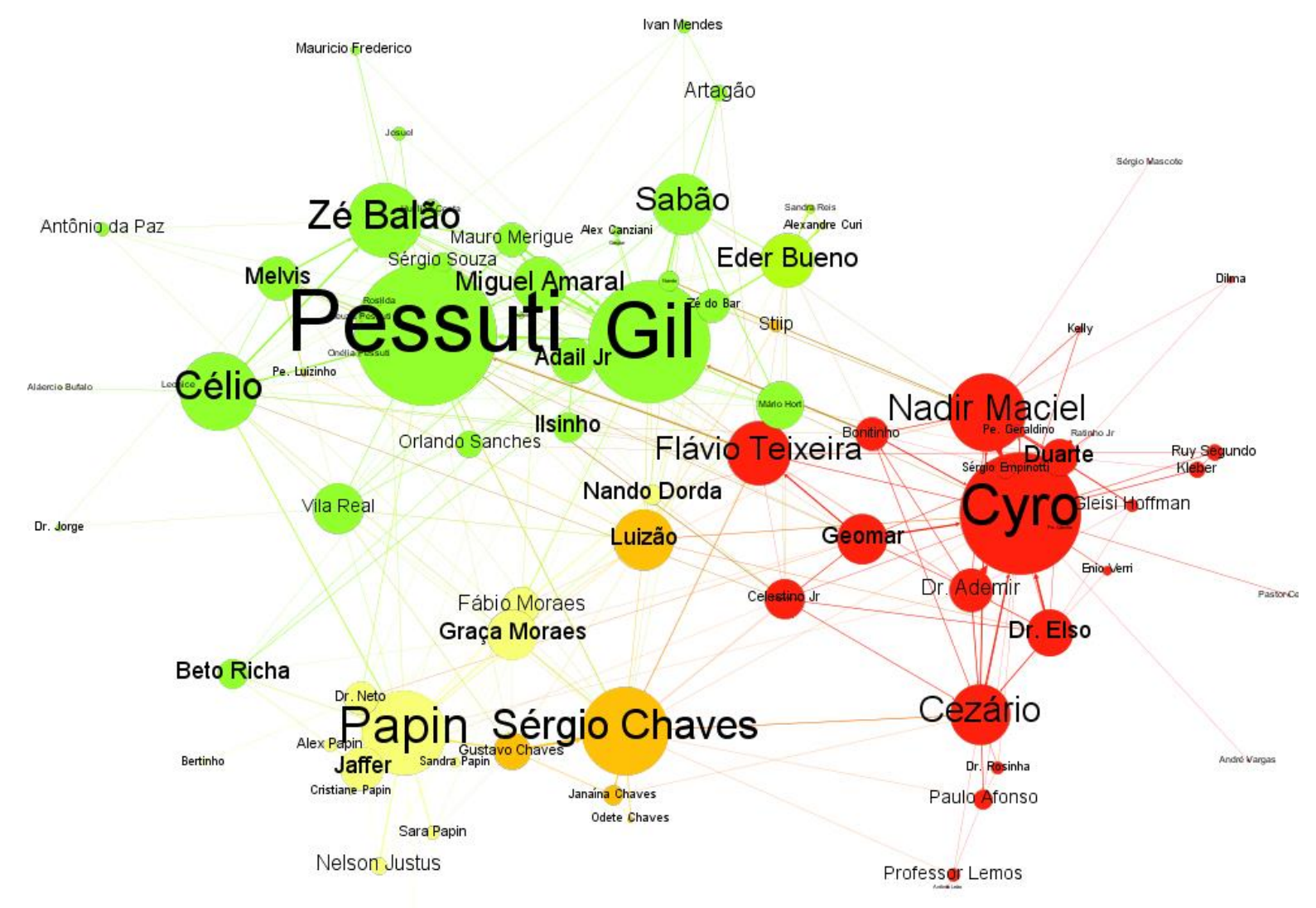

Figura1: Sociograma da rede de poder de Ivaiporã (2015) gerado pelo Gelphi 0.09.2 Org. por: Denez, Cleiton Costa (2015).

Produzir e ampliar vinculações e redes de poder implica estratégias como o uso do nepotismo, para formação, ampliação e consolidação de uma rede de poder. A prática de contratar parentes em cargos comissionados é tanto uma forma de controle do espaço público e de poder, quanto uma forma de assegurar a influência sobre as pessoas de determinado órgão e, assim, controlar áreas, se configurando enquanto territorialidade. A área, ou no nosso caso a prefeitura, secretaria e órgão regionais do estado estão sob o controle de alguém que

\footnotetext{
${ }^{25}$ Em Oliveira (2012, p. 13): "O nepotismo é uma grande rede social de interesses, favores e cumplicidades organizados com cargos políticos do aparelho do Estado". Há indícios que: "[...] surgiu nas relações políticas entre o Papa e os seus parentes, passando a definir todas as relações de parentesco na concessão de cargos ou privilégios a parentes, no funcionalismo público" (OLIVEIRA, 2012, p. 73). 
define quais as ações sobre determinado espaço se tornam uma territorialidade, enquanto estratégia de controle dos espaços públicos.

Em Ivaiporã, na administração de Papin, podemos evidenciar a candidatura de Jaffer a prefeito e a candidatura de Alex Papin ${ }^{26}$, genro e filho, respectivamente, de Pedro Papin; a candidatura de Graça Moraes $^{27}$, vice na chapa de Jaffer, candidato à prefeito em 2010, paralela à candidatura e eleição do filho Fábio $\operatorname{Moraes}^{28}$, candidato a vereador e, ainda, as nomeações de cargos das regionais do gorverno do estado. Todas essas nomeações e vinculações demonstram a formação de uma teia de nepotismo em torno de Pedro Papin e, consequentemente, uma estratégia para controle de determinados espaços de poder político no município de Ivaiporã.

Há, também, a inserção da família Papin em outros segmentos, como o magistério, Terezinha Papin, irmã de Pedro Papin, e suas filhas: Sara Papin ${ }^{29}$ e Sandra Papin $^{30}$, são professoras e estão inseridas nos espaços das escolas estaduais de Ivaiporã, ambas ocuparam direções de colégios estaduais. Sara Papin foi chefe do Núcleo Regional de Educação, nomeada por Jaime Lerner ${ }^{31}$ (PFL), em 1995, e, posteriormente, por Beto Richa ${ }^{32}$ (PSDB), em 2011, nomeações feitas por indicação do deputado estadual Nelson Justus ${ }^{33}$ ( PFL $^{34} / \mathrm{DEM}$ ) por influência de Pedro Papin.

Sandra Papin foi secretaria municipal de educação na gestão do Pedro Papin e depois ocupou cargos no Núcleo Regional de Educação por indicação de Papin ao Governador Beto Richa, além de diretora eleita de escola estadual. A formação de vínculos de parentesco pode ocorrer em diferentes órgãos públicos e funções dentro do Estado, tanto no executivo, quanto legislativo e até no judiciário. No executivo, como lembra Oliveira (2012), pode ser

\footnotetext{
${ }^{26}$ Empresário; filho de Pedro Wilson Papin; candidato a vice-prefeito na chapa de Pedro Wilson Papin em 2008 e chefe da Regional de Trabalho e emprego em Ivaiporã no Governo Beto Richa (PSDB).

${ }^{27}$ Maria das Graças Rocha de Moraes, professora da rede estadual; eleita vereador em 1982 e 1988 pelo PMDB e 1992 pelo PST. Chefe do Núcleo Regional de Educação. Candidata a vice-prefeita na chapa de Jaffer em 2012 pelo PSDB.

${ }^{28}$ Farmacêutico; filho de Graça Moraes. Eleito vereador em 2012 pelo PSDB.

${ }^{29}$ Sara Rodrigues Papin, professora da rede estadual. Chefe do Núcleo Regional de Educação de Ivaiporã nos governos Jaime Lerner (1996-2002) e no Governo Beto Richa (2010-2014).

${ }^{30}$ Sandra Rodrigues Papin, sobrinha de Pedro Wilson Papin; professora da rede estadual. Secretaria municipal de educação na gestão Papin (2001/2004); ex-diretora da Escola Estadual Idália Rocha.

31 Prefeito de Curitiba nos mandatos: 1971-1974/1979-1983/1989-1993. Governador do Paraná pelo PDT (1995/1998) e pelo PFL (1999-2002). Partidos aos quais foi filiado: ARENA/PDS/PDT/PFL/DEM/PSB.

${ }^{32}$ Carlos Alberto Richa, engenheiro, filho do ex-governador José Richa, ex-deputado estadual, ex-vice-prefeito e prefeito de Curitiba; Governador do estado do Paraná pelo PSDB (2011/2014-2015/2018).

${ }^{33}$ Advogado, eleito deputado estadual em 1990 pelo PFL e reeleito em 1994, 1998, 2002, 2006, 2010, 2014 e 2018. Secretário estadual de Indústria e Comércio no governo Jaime Lener, Presidente da ALEP em 2000 e reeleito em 2007.

${ }^{34} \mathrm{O}$ PFL, em 2007, passou a adotar a nova denominação de Democratas (DEM).
} 
facilmente verificáveis pelos nomes influentes, como no caso de Ivaiporã que temos a presença do nome Papin ocupando diferentes pastas e órgão públicos.

Da mesma forma que Raffestin (1993) explica, há vários trunfos no desenvolvimento da rede política de Ivaiporã, onde cada ator ou grupo detém trunfos desenrolando a trama pela posse do poder municipal. Entretanto, dificilmente determinado grupo arriscará todos os seus trunfos ou controlará por completo a rede, estabelece-se assim uma divisão de recursos, meios e estratégias no interior da teia de poder. Em consequência, em toda relação a organização os coloca total ou parcialmente em jogo (RAFFESTIN, 1993, p. 59). À medida que se desequilibra o jogo pela assimetria de recursos controlados e utilizados pelos grupos se dá a dominação de um sobre o outro.

No caso do grupo do PT, Cezário Benedito Pedro ${ }^{35}$, professor, Presidente do Partido dos Trabalhadores e Presidente do Núcleo Sindical de Ivaiporã da APP/Sindicato ${ }^{36}$, possui vínculo com as escolas estaduais no município de Ivaiporã, influindo nestes espaços com a presença de diretores, professores e funcionários. Cyro Fernandes carrega o título de "professor" ligado ao nome político: "Professor Cyro", construindo, assim, uma identificação com esse segmento, reforçado pela organização da APP-Sindicato, nas escolas estaduais e de outros segmentos da educação, como as escolas municipais e de professores que atuam na rede privada de ensino.

O Grupo do Professor Cyro/PT possuiu os meios para influenciar determinados espaços, como o meio simbólico, seja pela identificação da figura do "professor" e os meios materiais, como o controle do sindicato e de segmentos das escolas estaduais, seja por meio das pessoas que ocupam esses espaços, controlando, assim, as pessoas, os espaços e viceversa. Esse controle não se expressa de forma absoluta, não quer dizer que todos que estão presentes no cenário apresentado se reconhecerão nas práticas e ideologias do grupo e ator apresentado.

Outro nome vinculado ao Professor Cyro é Nadir Maciel, secretária de Indústria e Comércio na gestão petista e eleita vereadora pelo PT em 2012. Nadir, com os segmentos que representa, possui acesso a outros espaços, outros discurso e práticas ideológicas enquanto recurso, agregando esses segmentos ao grupo do Professor Cyro, ou ao Partido dos Trabalhadores de Ivaiporã. Na Composição do Secretariado da gestão do Professor Cyro há

\footnotetext{
${ }^{35}$ Cezário Benedito Pedro, professor da rede estadual; candidato a vereador pelo PT em 1996; Presidente do núcleo sindical da APP/Sindicato de Ivaiporã (2009/2011-2012/2014 e 2015/2017); Presidente do diretório municipal do Partido dos Trabalhadores.

${ }^{36}$ Sindicato dos profissionais de educação pública do Paraná, possuí direção estadual com sede em Curitiba e vinte e nove núcleos sindicais, entre eles o núcleo sindical de Ivaiporã.

Denez e Silva, 2019. 
outros nomes que represetam demais campos simbólicos do grupo, como o Padre Geraldino Rodrigues Proença ${ }^{37}$, secretário de educação, ligado às Pastorais de Fé e Política, da Terra e da Juventude, o que culmina com o apoio de outros párocos presentes em Ivaiporã. Pastor Cecílio Faustino Filho ${ }^{38}$, líder local da Assembleia Madureira e filiado ao Partido Social Cristão (PSC), contribuindo com o apoio de outros segmentos evangélicos. Verifica-se, assim, a entrada e controle dos segmentos religiosos, o que não é exclusividade. Porém, os demais grupos não possuem os mesmos interlocutores, o que diminui a eficácia da daminação política.

$\mathrm{Na}$ rede de poder representada pelo sociograma da figura 01, elaborado em 2015, é visível a assimetria, no qual as tessituras do grupo do PMDB se expandem, exercendo poder na maior parte dos espaços, porém dividindo espaço com o grupo do PT que se mantém distanciado do PMDB, por outro lado tem agido sobre o grupo de Papin expandido sua influência sobre nós antes polarizados pelo mesmo na complexa teia de poder. Ao mesmo tempo, é necessário destacar que o Grupo do PMDB não é coeso, da mesma forma que os demais, já que é formado por diferentes subgrupos, partido e nós intermediários, o que potencializa a chance de outros grupos expandirem sua ação sobre a rede em que as tessituras do PMDB alcançam no momento, retraindo a capacidade de exercício de poder do PMDB.

É possível verificar, ainda, vínculos externos ao território de Ivaiporã, nós de influência estadual e nacional, como o ex-governador Beto Richa, vinculado ao grupo de Papin e do PMDB; o ex-governador Roberto Requião, com vínculos entre diferentes grupos, no Partido dos Trabalhadores vínculos com o ex-presidente Lula, Dilma, senadora Gleisi Hoffmann, deputados estaduais e federais do partido. Para Saquet (2009), a partir das reflexões de Dematteis (1997), destaca que no território há relações internas e externas, assim, o os grupos políticos locais estão ligados a outras esferas por meio dos partidos e alianças estabelecidas e de outros elementos, como aqueles apontados por Castro (1992) sob a óptica dos interesses das repercussões no território. Saquet (2009) lembra, ainda, que as territorialidades são relações sociais simétricas ou dissimétricas que produzem historicamente cada território. Dessa maneira, identificar os atores e as relações que estabelecem entre os mesmos sobre determinado território contribui para compreender as relações assimétricas no

\footnotetext{
${ }^{37}$ Pároco vinculado às Pastorais de Juventude, Terra, Fé e Política. Secretário Municipal de Educação na gestão Cyro Fernandes (2008/2012).

${ }^{38}$ Cecílio Faustino Filho, Pastor da Igreja Assembleia Madureira; Membro do PSC; secretário municipal de assistência social na gestão Cyro Fernandes (2008/2012).
} 
processo de dominação e exercício do poder sobre determinado território, como no caso de Ivaiporã.

\section{CONSIDERAÇÕES}

O sociograma apresenta a rede de poder com três principais grupos que disputam território naquele município, cada grupo produz as tessituras de acordo às vinculações produzidas entre os nós. Há os mesmos atores para os diferentes nós e para o mesmo território, no caso Ivaiporã, então há territorialidades que disputam o exercício de poder sobre o território de Ivaiporã a partir da rede social política que se estabelece na presente malha territorial.

Evidenciam-se o grupo do PMDB polarizando o grande empresariado de Ivaiporã, comerciantes com vinculações com a Associação Comercial e Industrial de Ivaiporã (ACISI). Ainda há nós com vinculações com a Maçonaria, Rotary, Rádios Ubá/Ivaiporã FM, Jornal Paraná Centro e Grupo Comercial Ivaiporã. Com atores externos do cenário estadual: Beto Richa, Artagão, Alex Canziani, Alexandre Curi e Ademar Traiano. Os principais partidos polarizados pelo grupo: PP/PTB/PHS e PSDB.

No grupo do PT é polarizado parte dos professores e funcionários da rede estadual de ensino vinculado a APP/Sindicato; agricultores familiares, pequenos comerciantes, profissionais liberais e lideranças religiosas. Os atores externos pertencem ao próprio PT: Dilma Rousseff ${ }^{39}$, Gleisi Hoffmann ${ }^{40}$, André Vargas ${ }^{41}$, EnioVerri ${ }^{42}$, Dr. Rosinha ${ }^{43}$, exceto Ratinho $\mathrm{Jr}^{44}$ do PSC que é vinculado à Antônio Duarte ${ }^{45}$ que pertence ao PSC. Entre os partidos os principais são: PSC/PDT e o PPS que estabeleceu coligação na eleição de 2012.

\footnotetext{
${ }^{39}$ Ministra chefe da casa civil no Governo Lula e Presidenta da República (2010/2014-2015/2018).

${ }^{40}$ Formada em direito, integrante do PT desde 1989; eleita senadora em 2010, ministra chefe da Casa Civil no governo Dilma Rousseff e candidata ao governo do estado em 2014 pelo Partido dos Trabalhadores.

${ }^{41}$ Ex-vereador em Londrina; ex-presidente estadual do PT e ex-deputado estadual e federal.

${ }^{42}$ Professor da UEM, ex-deputado estadual e secretário de estado do governo Roberto Requião, eleito deputado federal pelo PT em 2014 e reeleito em 2018.

${ }^{43}$ Florisvaldo Fier, médico pediatra; ex-vereador em Curitiba; deputado estadual e federal pelo PT; Fundador do PT e da Central Única dos Trabalhadores (CUT). Atualmente é alto representante do MERCOSUL, candidato a governador pelo PT em 2018.

${ }^{44}$ Carlos Roberto Massa Junior, empresário de comunicação; filho de Carlos Roberto Massa; deputado estadual em 2002 pelo PSB, deputado federal em 2006 pelo PPS e deputado estadual em 2014 pelo PSC. Candidato a prefeito de Curitiba e secretário de estado no governo Beto Richa. Eleito Governador do Paraná em 2018 pelo PSD.

${ }^{45}$ Luiz Antônio Duarte, empresário, eleito vice-prefeito em 2008 na chapa de Cyro Fernandes. Candidato a deputado estadual em 2010 pelo PSC.
} 
No grupo Papin, os principais nós possuem vinculações de parentesco, a maior parte dos nós carregam o nome Papin: Alex Papin, Cristiane Papin, Sara Papin e Sandra Papin. Os principais atores são Pedro Papin e Jaffer Ferreira, embora o último não possua o nome Papin, a vinculação também se dá por parentesco. Os principais atores externos são: Nelson Justus e Beto Richa. Os principais partidos são: PTB/PSDB e DEM.

É necessário destacar a presença na rede de vários atores que provavelmente já tiverem posições de centralidade na rede, como as entrevistas para produção do sociograma foram realizadas entre os meses de março a junho de 2015 representam a configuração da rede neste momento. É necessário considerar, também, a evolução da rede ao longo do tempo, de acordo com o posicionamento de determinados atores e de vínculos com outros. Por outro lado, há determinados atores e vínculos que podem deixar a rede, que se altera com o tempo, porém, devem ser consideradas como produto das antigas vinculações e posicionamentos.

Outras entrevistas, após futuros pleitos eleitorais, podem revelar novos posicionamentos e vinculações dos atores políticos, e ainda novos atores, diminuindo determinados agrupamentos e aumentando outros, tornando periféricos atores antes centrais e vice-versa, ou até mesmo, manter a rede estável a depender dos arranjos políticos produzidos.

É necessário ressaltar que o sociograma apresentado (Fig.1), representa a acumulação de relações políticas estabelecidas em Ivaiporã ao longo tempo. Então, há vínculos representados que são antigos e não se estabelecem mais, porém as pessoas entrevistadas citaram diferentes vínculos, passados e presentes. Entretanto é notória a maior expressividade de citações de acordo com os vínculos que se estabelecem no momento que foi realizada a entrevista, principalmente, pautada nas últimas eleições municipais, no caso a eleição municipal de 2012, e as eleições gerais de 2014.

Por meio da rede, ainda é possível interpretar a correlação de forças entre os atores políticos é que não existe poder absoluto, é um jogo de trocas e permutas, onde cada nó exercer uma atividade a depender de onde se encontra e o que controla.

Assim, foi possível identificar os atores centrais da rede, bem como as principais vinculações que estabelecem possibilidades de acomodar recursos e estratégias utilizadas para o exercício de poder sobre o território. Fica, ainda, um elemento importante para futuras pesquisas, o de averiguar e aprofundar a análise de ações que indicam a hierarquia de poder desenhada e as ações efetivadas nas teias deste e de outros territórios, já que o estudo realizado em Ivaiporã pode ser utilizado como referência e modelo de análise para outros casos semelhantes. 


\section{REFERÊNCIAS}

ALEJANDRO, Velázques Álvarez; NORMAN, Aguilar Gallegos. Manual Introdutório à Análise de Redes Sociais. UAEM - Universidad Autonoma del Estado de México. 2005.

CASTRO, Iná Elias de. O mito da necessidade: discurso e prática do regionalismo nordestino. Rio de Janeiro: Bertrand Brasil, 1992.

DENEZ, Cleiton Costa. "Território em disputa: territorialidades, redes sociais e grupos políticos de Ivaiporã/PR (2000/2012)". Tese (Doutorado em Geografia) Universidade Estadual de Maringá (UEM), Maringá/PR, 2016.

FURINI, Luciano Antônio. Redes sociais temáticas: o caso das redes sociais de assistência à criança e ao adolescente em Presidente Prudente (SP) e suas representações sociais. 2008. 255 f. Tese (doutorado) - Universidade Estadual Paulista, Faculdade de Ciências e Tecnologia, 2008. Disponívelem: <http://hdl.handle.net/11449/101423>. Acessado em $13 / 11 / 2018$.

HAESBAERT, Rogério. Territórios alternativos. 2ª ed. Contexto. São Paulo, 2006. HANNEMAN, Robert A.; RIDDLE, Mark. Introduction to social network methods. Riverside, CA: University of California, Riverside (published in digital form at http://faculty.ucr.edu/ hanneman/), 2005. Acessado em 02.10.2015.

MALAGOLLI, Guilherme Augusto. Rede política no arranjo produtivo local calçadista de Jaú. 2010. 250 f. Tese de Doutorado. Universidade Federal de São Carlos: UFSCar. São Carlos SP.

MILLS, Charles Wright. A elite do poder. Tradução de Waltensir Dutra. Rio de Janeiro, Zahar Editores, 1968.

MIGUEL, Luis Felipe. Dominação e Resistência: desafios para uma política emancipatória. 1. ed. - São Paulo: Boitempo, 2018.

NAZARENO, Louise. Redes sociais e coalizão de poder em Curitiba (1985-2004). Dissertação de mestrado, São Paulo, USP/DCP. 2005.

OLIVEIRA, Ricardo Costa. Na Teia do Nepotismo: Sociologia Política das relações de parentesco e poder político no Paraná e no Brasil. Editora: Insight. Curitiba, 2012.

RAFFESTIN, Claude. Por uma geografia do poder. Tradução de Maria Cecília França. São Paulo: Ática, 1993.

RAFFESTIN, Claude. A produção das estruturas territoriais e sua representação. In: Territórios e territorialidade: teorias processo e conflitos. Organizado por Marcus Aurélio Saquet \&Eliseu SavérioSpósito. $1^{\mathrm{a}}$ ed. São Paulo. Expressão Popular: UNESP. Programa de Pós-Graduação em Geografia, 2009, p17- 35.

SAQUET, Marcos Aurélio. "Território" da divergência (e da confusão): em torno das imprecisas fronteiras de um conceito fundamental. In: Territórios e territorialidade: teorias processo e conflitos. Organizado por Marcus Aurélio Saquet \& Eliseu Savério Spósito. $1^{\mathrm{a}}$ ed. São Paulo. Expressão Popular: UNESP. Programa de Pós-Graduação em Geografia, 2009a. 
SAQUET, Marcos Aurélio. O território: diferentes interpretações na literatura italiana. In: Território e desenvolvimento: diferentes abordagens. Francisco Beltrão. PR. Unioeste, 2004.

SAQUET, Marcos Aurélio. Por uma Geografia das territorialidades e das temporalidades. $1^{a}$. Ed. Outras Expressões. São Paulo, 2011.

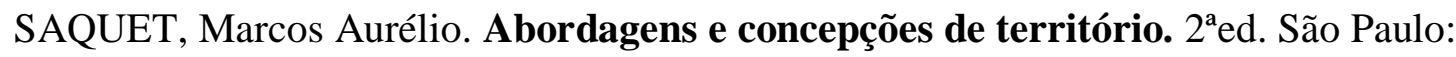
Expressão Popular, 2010.

SAQUET, Marcos Aurélio. Por uma abordagem territorial. In: Territórios e territorialidade: teorias processo e conflitos. Organizado por Marcus Aurélio Saquet \& Eliseu Savério Spósito. $1^{\text {a }}$ ed. São Paulo. Expressão Popular: UNESP. Programa de PósGraduação em Geografia, 2009b.

SILVA, Márcia da. Territórios conservadores de poder no centro-sul do Paraná. Tese de Doutoramento. Universidade Estadual Paulista, Faculdade de Ciências e Tecnologia (UNESP). Presidente Prudente. 2005.

SOUZA, Jessé. A elite do atraso: da escravidão a lava jato. Rio de Janeiro: Leya, 2017.

SOUZA, José Marcelo Lopes de. O território: sobre espaço e poder, autonomia e desenvolvimento. In: Geografia - conceitos e temas. Rio de Janeiro: Bertrand do Brasil, 1995. 